1Universidade Federal de Minas Gerais (UFMG)

- Belo Horizonte (MG), Brasil.

kelibahia@yahoo.com.br

\section{Projeto Gestão e Gentileza nos plantões noturnos de um hospital universitário: relato de experiência}

\author{
Management and Kindness Project: an approach on the night shift at \\ a university hospital

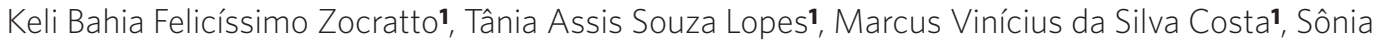 \\ Maria Nunes Viana', Mirela Castro Santos Camargos ${ }^{\mathbf{1}}$
}

DOI: $10.1590 / 0103-1104201912127$

RESUMO O presente estudo teve por objetivo descrever a experiência de implantação do Projeto de Extensão Gestão e Gentileza nos plantões noturnos de um hospital universitário, de janeiro a dezembro de 2017, explicitando a articulação entre o conhecimento teórico adquirido em diversas disciplinas do Curso de Gestão de Serviços de Saúde e a prática extensionista. O projeto, direcionado aos trabalhadores noturnos, buscou ressaltar a importância desses funcionários no ambiente hospitalar por meio de intervenções de gestão e gentileza em sete unidades do Hospital. A articulação entre teoria e prática perpassou pelas diversas etapas do projeto, contribuindo para a formação de profissionais capazes de intervir no cotidiano das organizações de saúde de maneira inovadora e efetiva. A vivência no projeto certificou a urgência de pensar intervenções permeadas por ações de gentileza em que todos os profissionais tenham condições de participar e se beneficiar com os resultados.

PALAVRAS-CHAVE Equipe de assistência ao paciente. Gestão em saúde. Hospitais universitários. Jornada de trabalho em turnos.

\begin{abstract}
The present study aims to describe the experience of implementing the Extension Project Management and Kindness in the night shifts of a university hospital, from January to December 2017, showing the articulation between the theoretical knowledge acquired in several subjects of the Health Services Management Course and the extension practice. The project, aimed at night workers, sought to highlight their importance in the hospital environment by means of management and kindness in seven hospital units. The articulation between theory and practice permeated the various stages of the project, contributing to the formation of professionals capable of intervening in the daily life of health organizations in an innovative and effective way. The experience in the project certified the urgency to think of interventions permeated by actions of kindness in which all professionals are able to participate and benefit from the results.
\end{abstract}

KEYWORDS Patient care team. Health management. Hospitals,university. Shift work schedule. 


\section{Introdução}

A extensão universitária propicia a formação de um profissional cidadão ao permitir a ampliação do processo educativo, cultural e científico, estruturando, com o ensino e a pesquisa, o processo de construção do conhecimento. A prática extensionista acontece ancorada no diálogo, proporcionando experiências únicas aos alunos fora do ambiente acadêmico. Constrói uma via de mão dupla, em que a universidade não só leva conhecimento à comunidade como também aprende com os saberes populares, sendo, dessa maneira, provedora de conhecimento'.

A participação em atividades extensionistas estabelece um diferencial na formação dos alunos, qualificando-os para que se tornem profissionais capazes de intervir no cotidiano das organizações de maneira inovadora e efetiva ${ }^{1-3}$. Estar inserido nas atividades organizacionais cotidianas possibilita a articulação entre a teoria e a prática, desafiando os participantes a encararem diversidades presentes a todo o momento nos campos de atuação extensionista, fazendo desta uma experiência de enfrentamento que acelera e consolida o aprendizado ${ }^{2}$.

A participação em um projeto de extensão oferece aos alunos uma ampla reflexão sobre questões éticas, trato solidário, caráter, cidadania e responsabilidade social. Possibilita o desenvolvimento de habilidades, como saber observar e ouvir, refletir para compreender, intervir em benefício da coletividade ${ }^{2}$. Os extensionistas têm a oportunidade de trocar experiências e informações com os profissionais que trabalham nas organizações onde realizam intervenções, estabelecendo vínculos que fomentam a construção de mecanismos mais efetivos na melhoria das condições de trabalho desses funcionários.

O processo de organização e planejamento do trabalho hospitalar engloba fatores técnicos, econômicos, políticos, culturais e profissionais, sendo necessário estimular o compartilhamento de experiências, interação e corresponsabilização de todos os atores em prol de um ambiente de trabalho saudável ${ }^{3}$. Os projetos de extensão podem ser considerados facilitadores da realização dessas demandas, sendo fundamental na harmonização das relações entre a imensa diversidade de profissionais que atuam nas organizações de saúde 4 .

As atividades nas organizações de saúde, com destaque para os hospitais, são predominantemente coletivas, organizadas e realizadas, em partes, por diferentes profissionais ${ }^{5}$. Os grupos de profissionais que trabalham nos hospitais dominam os conhecimentos das atividades relativas à sua qualificação profissional, apresentando, muitas vezes, dificuldades na articulação entre a área da assistência e da gestão. Executam tarefas delegadas, com certo arbítrio para decisões, desde que elas não contradigam as normas técnicas e/ou as decisões superiores. Esse cenário pode suscitar nos trabalhadores um sentimento de não ser parte integrante do todo, contribuindo para a perda de ânimo na realização das tarefas e de compromisso com o objetivo final do seu processo de trabalho5,6.

Agrega-se a esse sentimento de não pertencimento comum aos trabalhadores da área hospitalar, a conclamação feita pelos trabalhadores noturnos quanto a pouca visibilidade e valorização de seu trabalho. Os turnos de trabalho nos hospitais suprem a necessidade de prestar cuidado ininterrupto e atender à demanda da população por atendimento, inclusive no período noturno ${ }^{7}$.

Considerado contrário à natureza do ser humano, que possui ritmo biológico diurno, o trabalho noturno interfere no bem-estar físico-mental e social do trabalhador. Diminui seu desempenho na realização de suas tarefas, prejudicando também as suas relações familiares e sociais ${ }^{8}$. As atividades noturnas acontecem longe dos holofotes da rotina hospitalar diurna, dos eventos comemorativos, da realização de cursos, visitas de acadêmicos, entre outros. Distanciamento que também afeta, entre outras coisas, o estado de ânimo do trabalhador e potencializa a sensação de pouca visibilidade e valorização. 
Cabe dizer que as relações de trabalho sempre serão permeadas por problemas, não somente pelos motivos acima citados, mas também gerados pelas hierarquias constituídas, valorização de determinadas profissões em detrimento de outras, distribuição de poder diferenciada e/ou desigual, ou mesmo características individuais dos trabalhadores ${ }^{8}$.

No ambiente hospitalar, ressaltam-se os problemas ligados à pouca satisfação e ao desânimo dos trabalhadores com suas funções dentro das equipes. No caso de trabalhadores noturnos, a situação tende a ser mais complexa; pois, em alguns casos, o gestor possui horário de trabalho exclusivamente diurno. Nessas situações, mesmo tendo outro profissional que realize a ponte entre as partes, os trabalhadores se ressentem dessa distância, podendo ser considerado como um fator que alimenta o sentimento de pouca valorização e visibilidade entre os trabalhadores noturnos. De modo geral, apesar de terem diferentes origens, esses problemas recebem um tratamento parecido, sem haver uma atenção individualizada, o que demonstra uma tendência à repetição de padrões institucionais ${ }^{6}$.

Foi observando os trabalhadores noturnos de um hospital universitário, no que se refere às condições de trabalho e à qualidade de vida no trabalho em uma das disciplinas da graduação em Gestão de Serviços de Saúde/UFMG (Universidade Federal de Minas Gerais), que o Projeto Gestão e Gentileza, objeto do presente estudo, construiu suas bases. Os relatos dos trabalhadores evidenciavam a influência negativa do sentimento de pouca visibilidade e valorização de seu trabalho em seu estado de ânimo.

Diante de demandas tão urgentes e complexas, o projeto, com uma postura ousada, inovadora e acolhedora, buscou desenvolver ações específicas de gestão e gentileza, arranjadas de maneira simples, humanizada e direta nas unidades de um hospital universitário em que acontecem atividades noturnas.

Nesse sentido, o presente estudo tem por objetivo descrever a experiência de implantação do Projeto Gestão e Gentileza, explicitando a articulação entre o conhecimento teórico adquirido em diversas disciplinas do Curso de Gestão de Serviços de Saúde e a prática extensionista, na perspectiva dos discentes integrantes da equipe de trabalho.

\section{Metodologia}

Trata-se de um estudo descritivo de natureza qualitativa na modalidade de relato de experiência, a partir das reflexões dos alunos do Curso de Gestão de Serviços de Saúde, que participaram do Projeto de Extensão Gestão e Gentileza nos plantões noturnos de um hospital universitário em Minas Gerais, de janeiro a dezembro de 2017, primeiro ano do projeto.

O projeto foi direcionado aos profissionais que atuam no hospital, em plantões noturnos, independentemente da categoria deles. As intervenções foram realizadas em cinco unidades fechadas do hospital - Serviço de Nutrição e Dietética (SND), Central de Material Esterilizado (CME), Centro de Terapia Intensiva Adulto (CTI), Unidade Coronariana (UCO), Higienização - e em duas unidades abertas - Pronto Atendimento (PA) e recepção. A frequência dessas intervenções foi determinada pelo número de escalas dos trabalhadores (duas ou três) e tinha duração de 15 minutos cada.

Foi dividido em duas etapas que aconteceram nas unidades do hospital em momentos distintos ou simultâneos, a saber: etapa Gentileza e etapa Gestão. Utilizando abordagens de Gentileza, o grupo realizou intervenções com apresentações lúdicas de curta duração. Na etapa relacionada com a Gestão, os alunos elaboraram uma intervenção efetiva para melhoria da comunicação entre a gestão e os trabalhadores noturnos na Unidade de Higienização. As ações foram realizadas pelos 12 alunos que participaram na primeira abordagem do projeto (Gentileza); e por 10 alunos na segunda abordagem (Gestão). 


\section{Resultados e discussões}

A elaboração e a implantação do Projeto Gestão e Gentileza foram bastante desafiadoras, pois requereu de seus integrantes uma postura proativa, dialógica e criativa na construção das ações, assim como exigiu o desenvolvimento e aprimoramento de habilidades relacionadas com a gestão de pessoas. A vivência prática da disciplina de Administração Hospitalar, realizada por meio de visitas às unidades do hospital universitário, foi precursora para o desenvolvimento do projeto.

Nessas visitas, os discentes buscaram, por meio da aproximação com os trabalhadores noturnos, captar e conhecer sua realidade; uma vez que o conhecimento da realidade no ambiente de trabalho clarifica a relação entre teoria e prática ${ }^{8}$. Nesses momentos, os trabalhadores noturnos deixavam transparecer seus sentimentos quanto à pouca visibilidade e valorização de seu labor. Por trabalharem longe da rotina hospitalar diurna, pouco participavam dos eventos comemorativos, da realização de cursos, de visitas acadêmicas, sentindo-se esquecidos; o que afetava no reconhecimento de suas práticas, pois entendiam que a realização do seu trabalho era pouco percebida dentro da rotina hospitalar. Acrescido a isso, a dificuldade em participar de espaços que são promovidos no período diurno, como encontros de educação permanente, reuniões informativas e comemorativas, cursos sobre novas rotinas ou equipamentos, contribui para o desconhecimento das novas tecnologias a serem utilizadas no serviço 9 .

A ausência física de um gestor durante o período de trabalho noturno pode ser uma variável que colabora para o aumento do sentimento de pouca valorização. $\mathrm{O}$ distanciamento físico entre a gestão diurna e os trabalhadores noturnos dificulta a comunicação entre as partes de modo que as demandas dos trabalhadores são passadas aos encarregados, e só então repassadas ao gestor.

Diante do cenário apresentado, o projeto foi divido em duas abordagens: Gentileza e
Gestão. Para dar início às atividades do projeto, os alunos utilizaram os conhecimentos adquiridos na disciplina Elaboração e Gestão de Projetos, que apresenta ferramentas a serem utilizadas para o conhecimento e elaboração de estratégias de intervenção na realidade e/ou situações consideradas coletivamente como indesejadas ${ }^{10}$. Dessa maneira, a partir da problematização da situação (foco da intervenção), seguiu-se para a definição da metodologia com a descrição do caminho a ser adotado para implementação do projeto. Nesse momento, levantou-se a possibilidade de se utilizar diversos métodos, como roda de conversas, observação ativa, questionários, dinâmicas de grupo e apresentações lúdicas. Além disso, percebeu-se a necessidade de criar uma marca representativa do projeto. Uma árvore, tendo no lugar de folhas, borboletas multicoloridas, foi escolhida como símbolo; uma vez que faz analogia ao trabalho noturno e seus desafios. Dessa maneira, entende-se que o tronco de uma árvore proporciona sustentação aos seus frutos; assim como o trabalho noturno, ao funcionamento do hospital.

A borboleta, presente na marca representativa do projeto, simboliza a transformação que também é desejada pelos trabalhadores noturnos no que ser refere à maior visibilidade e reconhecimento de seu trabalho. Para representar a passagem do projeto pelas unidades, foi construída uma árvore para cada unidade visitada. As borboletas seriam distribuídas aos trabalhadores da unidade para que preenchessem com seus nomes e/ou desejos e, posteriormente, penduradas na árvore.

O grupo de alunos responsável pela abordagem de Gentileza, visando atenuar o sentimento de pouca visibilidade e valorização do trabalho noturno declarado pelos trabalhadores, desenvolveu ações específicas que exteriorizavam humanização e gentileza. A gentileza é considerada uma ferramenta bastante eficiente uma vez que tem o poder de fortalecer ações positivas, modificar as pessoas e estimulá-las a se dedicarem cada vez mais às suas atividades ${ }^{11}$. Com o intuito de 
proporcionar a prática de gentileza, utilizou-se uma metodologia provocativa com o uso de ferramentas lúdicas de modo a estimular a participação dos trabalhadores. Atividades lúdicas promovem maior interação do público-alvo (trabalhadores noturnos) com o interlocutor (alunos do projeto), ultrapassando a barreira entre os atores da intervenção. Os interesses tornam-se os mesmos; experiências e vivências são trocadas, conhecimentos e informações são construídos pelos envolvidos ao longo de todo o processo ${ }^{12}$.

A definição dos setores que efetivamente participariam do projeto se deu a partir do mapeamento das unidades do hospital universitário que possuíam atividades laborais noturnas, sendo realizado pela equipe Gentileza no primeiro semestre de 2017. Em sequência, foi apresentado o projeto aos gestores das respectivas unidades, obtendo autorização e apoio para realização das atividades, acordando datas e horários.

O projeto sustentou suas ações na ética, trato solidário, cidadania e responsabilidade social, questões amplamente discutidas no Curso de Gestão de Serviços de Saúde/UFMG, com destaque para as disciplinas: Ética e Bioética, Gestão das Relações de Trabalho, Relações de Poder nas Organizações de Saúde. A articulação entre a teoria e prática proporcionada pela execução do projeto será resgatada em momentos oportunos durante a apresentação das diversas ações desenvolvidas no projeto.

Considerando que o público-alvo eram trabalhadores noturnos que, em sua maioria, apresentavam estado de ânimo afetado negativamente, foi necessário lançar mão dos conhecimentos adquiridos na disciplina Liderança e Gestão das Organizações de Saúde. Esta disciplina, entre outros temas, aborda a importância das emoções para aumento do vínculo dentro das organizações, pois controlam as relações entre os indivíduos e o meio onde se encontram. Nesse sentido, apreender e compreender os diversos aspectos referentes às crenças, aos comportamentos e desafios vivenciados pelos trabalhadores noturnos foi essencial, assim como estabelecer um momento diferenciado capaz de atingir os trabalhadores noturnos por meio da emoção. A abordagem utilizada deveria favorecer a aproximação entre os envolvidos, e a intervenção deveria ser direta e tocante. Dessa maneira, escrevendo nas borboletas desejos, opiniões e impressões sobre o tema, os trabalhadores contribuíram para a realização da atividade em uma clara demonstração de confiança.

Em todos os encontros, foi realizada apresentação de paródia musical e distribuição de mensagens com reflexões sobre o efeito da gentileza no ambiente profissional (as mensagens foram escritas em cartões com a forma de borboleta e afixadas em chocolates). Foram deixadas a árvore representativa da passagem do projeto na unidade e as borboletas preenchidas pelos trabalhadores. A utilização do lúdico nos encontros permitiu aos trabalhadores noturnos, mesmo que momentaneamente, um distanciamento da realidade, dando a eles a sensação de plenitude, liberdade e alegria ${ }^{4}$.

As ações desenvolvidas começavam a distanciar os sentimentos de exclusão, revolta, desprezo e de isolamento que os trabalhadores noturnos tinham em relação ao restante do grupo ${ }^{\mathbf{1 3}}$. A pertinência do projeto, a cada momento, mostrava-se mais evidente, uma vez que proporcionava aos trabalhadores a sensação de bem-estar, melhora da autoestima, redução dos níveis de tensão, maior socialização, valorizando os laços de companheirismo e amizade; enfim, sentimentos efetivos na dispersão da sensação de pouca visibilidade e valorização do trabalho. Ter um projeto direcionado exclusivamente para eles aguçou a sua percepção do quanto o trabalho noturno é importante e de que também são agentes participativos no processo.

A necessidade de um olhar diferenciado sobre as inquietações dos trabalhadores ficou evidente ao longo da implementação do projeto, e isso estimulou a utilização de diversos modelos de intervenções. Abordagens compostas por gestos simples, com resgate de valores esquecidos, por meio de atividades 
que estimulem atitudes positivas que devem ser expressas por todos, independentemente da categoria profissional, tornam o ambiente de trabalho mais saudável. São pequenos detalhes do cotidiano de trabalho que contribuem para evitar e/ou minimizar o surgimento de conflitos dentro do ambiente. Essa foi uma das contribuições que a disciplina Relações de Poder nas Organizações de Saúde trouxe ao projeto, uma vez que desenvolveu habilidades e competências para o entendimento das relações de poder e o seu manejo dentro de uma organização de saúde.

O reconhecimento do trabalho realizado no projeto veio por meio de demonstrações afetuosas dos trabalhadores ao término dos encontros de gentileza e do recebimento do título de 'grupo das borboletas'. O convite de gestores para a realização de encontros em outras unidades noturnas e diurnas também demonstrou que o projeto apresentava consonância com as demandas do serviço e que ações de gentileza deveriam ultrapassar a dicotomia dia/noite para, efetivamente, serem incorporadas às relações pessoais. Uma maior visibilidade do Curso de Gestão de Serviços de Saúde na comunidade do hospital universitário também pôde ser notada.

O grupo da abordagem Gentileza teve sua equipe renovada no segundo semestre de 2017 e realizou intervenções nas unidades abertas (Pronto Atendimento e Recepção). As atividades foram adaptadas, pois o público a ser alcançado se ampliou. Além dos trabalhadores noturnos, as ações atingiriam também os usuários e transeuntes. Os alunos participantes utilizaram placas com mensagens sobre gentileza penduradas no próprio corpo, para chamar a atenção do público do hospital, entoando paródia musical e distribuindo mensagens reflexivas sobre o efeito positivo da gentileza em qualquer ambiente.

As abordagens relativas à Gestão iniciaram suas primeiras atividades no segundo semestre de 2017, sendo a equipe formada pelos participantes da abordagem de Gentileza do primeiro semestre. A unidade escolhida para realização das atividades foi a Higienização, pelo acolhimento recebido dos trabalhadores na abordagem Gentileza e pela deferência de sua gestora.

A abordagem Gestão ficou responsável por intervir na questão relacionada com a comunicação entre a gestão e os trabalhadores. Decidiu-se que a melhor estratégia a ser utilizada na intervenção seria a observação ativa e diálogos informais com os profissionais da unidade. Escolheu-se a observação, pois é uma técnica que dá a possibilidade de obter informações de maneira espontânea, em que o observado se sente à vontade em falar de suas funções cotidianas, mostrando a realidade no momento ${ }^{14}$. A decisão de qual metodologia utilizar foi discutida entre o grupo e, no momento inicial, não foi consensual. A resistência à metodologia proposta teve que ser superada a partir de uma construção coletiva e dialógica, fundamentos essenciais presentes em atividades extensionistas, de maneira geral ${ }^{5}$.

Dessa maneira, o projeto desafiou as habilidades desenvolvidas em disciplinas como Liderança na Gestão das Organizações de Saúde em que se discutem as dificuldades de unificação de visões sobre atividade a ser realizada em equipe. A diversidade de opiniões é fator gerador de conflitos no ambiente de trabalho. Os conflitos podem ser avaliados a partir de uma perspectiva negativa ou positiva. Considerado negativamente, o conflito pode provocar reações distintas no âmbito das organizações, comprometendo a realização de objetivos e metas ${ }^{15}$. Em sua abordagem positiva, os questionamentos que o conflito aponta podem servir como forma de estímulo para o desenvolvimento de conhecimentos e habilidades, contribuindo para inovações dentro de suas organizações.

Na questão pertinente às escolhas e decisões relativas ao projeto, o grupo optou por aproveitar o lado positivo do conflito dentro da equipe. Dessa maneira, o conflito desencadeou uma melhora na qualidade das decisões, estimulando a criatividade e a 
inovação, além de ter despertado interesse e curiosidade entre membros da equipe. Nesse sentido, foram realizadas diversas reuniões; e, com o exercício da paciência e exposição clara e segura da metodologia, aqueles resistentes começaram a compreender que o importante é a união de conhecimentos e ideias para detectar os problemas reais e buscar soluções originais e criativas.

Depois de ter decidido coletivamente a metodologia a ser utilizada, iniciaram-se os encontros na Unidade de Higienização. Eles aconteceram durante seis dias, atingindo as duas escalas de trabalho da unidade. O tempo de duração dos encontros foi de 15 minutos, sendo norteados por um roteiro construído previamente com vistas a direcionar o desenvolvimento das atividades. Estabeleceu-se uma sequência de ações que se iniciaria por uma rápida apresentação do grupo, dos objetivos do projeto, dinâmica da distribuição e preenchimento das borboletas, seguido pela apresentação da paródia e agradecimento pela acolhida.

Durante os encontros, os diálogos informais deixaram transparecer que as inquietações relatadas pelos trabalhadores giravam em torno de questões cotidianas do seu trabalho, como: retirada de lanche, troca de ticket, advertência sem conversa, divisão de trabalho, falta de união, falta de parceria de outros grupos de profissionais. Nesse contexto, considerando a vivência experimentada no grupo Gentileza, percebeu-se que, na verdade, os trabalhadores precisavam de um pouco mais de gentileza e clareza da gestão na exposição das mudanças e/ou inclusão de novas regras. $\mathrm{O}$ trabalhador, em certa medida, precisava ser visto como um agente participativo de um processo, e não meramente um depositário de regras, normas e informações. Nesse momento, a dificuldade de gerir conflitos fez emergir a ideia de que não se podem gerir pessoas, e deve-se, sim, gerir com as pessoas ${ }^{\mathbf{1 6}}$.

Terminados os encontros, as inquietações dos trabalhadores foram organizadas e agrupadas, preservando-se o seu anonimato e apresentadas ao gestor que, posteriormente, realizaria uma devolutiva aos trabalhadores a respeito das demandas identificadas e apresentadas.

Nesse sentido, finalizou-se o primeiro ciclo do projeto com o fechamento das etapas Gentileza e Gestão. Procedeu-se à avaliação com a presença de todos os participantes do projeto, em que foram identificadas as dificuldades encontradas para operacionalização das atividades bem como o desempenho dos envolvidos. Esse encontro proporcionou a exposição por cada participante de seu sentimento em relação à participação no projeto, sua opinião sobre a metodologia aplicada pelo projeto e o entendimento de que o Projeto Gestão e Gentileza é um instrumento reflexivo de construção coletiva.

\section{Considerações finais}

O graduando de Gestão de Serviços de Saúde precisa, além de competências técnicas, aperfeiçoar habilidades direcionadas ao gerenciamento das relações interpessoais e aprofundar seus conhecimentos sobre a gestão com as pessoas. A sua formação precisa atingir para além do saber técnico, sendo essencial fundamentar-se em atitudes éticas, integridade moral, empatia e autoconhecimento. Nesse sentido, o projeto de extensão, por meio de atividades interdisciplinares teórico-práticas, apresenta-se como alternativa efetiva na complementação do ensino na graduação. Proporciona a articulação entre teoria e prática exigindo um resgate do conhecimento adquirido para solucionar questões presentes na realidade, o que foi observado, no presente relato, pela presença de conteúdos abordados em disciplinas como Administração Hospitalar, Ética e Bioética, Gestão das Relações de trabalho, Relações de Poder nas Organizações de Saúde, entre outras.

O trabalhador noturno é parte fundamental de uma engrenagem na qual os serviços são realizados de maneira ininterrupta para que a 
população não seja prejudicada. O profissional responsável pela gestão deve ser sensível aos motivos que afetam de maneira negativa o bem-estar e a saúde desses trabalhadores. O Projeto de Extensão Gestão e Gentileza apresentou, em suas duas abordagens, resultados satisfatórios. Em relação à etapa Gentileza, foi capaz de melhorar o estado de bem-estar dentro das equipes de saúde que trabalham no período noturno. Ao utilizar o emprego de diferentes estratégias, proporcionou o envolvimento dos trabalhadores de diferentes níveis hierárquicos, promovendo aprendizado e troca de conhecimento, além de sensibilizar os trabalhadores quanto à necessidade de construção coletiva para um ambiente laboral mais saudável, onde todos têm sua importância.

No que tange à etapa Gestão, o projeto evidenciou a importância da participação do gestor como facilitador dessa harmonização no ambiente de trabalho ao facilitar a interação entre os membros da equipe, proporcionando uma sensibilização e mobilização coletiva, mantendo sempre aberto um canal para negociação. Além disso, observou-se que a presença física do gestor na equipe pode ajudar a expandir os conhecimentos e habilidades do grupo, gerando cooperação, esforço em prol de um objetivo comum, o que minimiza conflitos e instabilidades do cotidiano de trabalho. Nesse sentido, a articulação entre teoria e prática vivenciada no Projeto Gestão e Gentileza proporcionou aos alunos a visualização da difícil e complexa articulação entre o saber e o fazer na gestão dos serviços de saúde.

\section{Colaboradores}

Zocratto KBF (0000-0002-5742-0570)*, Lopes TAS (0000-0002-6634-9884)*, Costa MVS (0000-0002-9173-3861)*, Viana SMN (0000-0001-7176-9974)* e Camargos MCS, (0000-0003-1151-3533)* contribuíram para a concepção, planejamento, análise, redação, revisão crítica e aprovação final do artigo.

\section{Referências}

1. Silva AFL, Ribeiro CDM, Silva Júnior AG. Pensando extensão universitária como campo de formação em saúde: uma experiência na Universidade Federal Fluminense, Brasil. Interface (Botucatu) [internet]. 2013 [acesso 2018 jan 15]; 17(45):371-384. Disponível em: http://dx.doi.org/10. 1590/S141432832013000200010.

2. Martins EF. Extensão como componente curricular: oportunidade de formação integral e de solidariedade. Cien. Cogn. 2008; 13(2):201-209.
3. Uchoa AC, Vieira RMV, Rocha PM, et al. Trabalho em equipe no contexto da reabilitação infantil. Physis [internet]. 2012 [acesso 2018 jan 3]; 22(1):385400. Disponível em: http://dx.doi.org/10.1590/S010373312012000100021.

4. Campos GW. Subjetividade e administração de pessoal: considerações sobre modos de gerenciar o trabalho em equipes de saúde. In: Merhy EE, Onocko $\mathrm{R}$, organizadores. Agir em saúde - um desafio para o público. São Paulo: Hucitec; 1997. p. 229-266.
${ }^{*}$ Orcid (Open Researcher and Contributor ID). 
5. Pereira RCA. O trabalho multiprofissional na Estratégia Saúde da Família: estudo sobre a modalidade das equipes [dissertação] [internet]. Rio de Janeiro: Fundação Oswaldo Cruz; 2011. 135 p. [acesso em 2018 jan 7]. Disponível em: https://www.arca.fiocruz.br/ bitstream/icict/23245/1/933.pdf.

6. Pires DA. Reestruturação produtiva e trabalho em saúde no Brasil. Rev. Bras. Enferm. 2000; 53(2):251263.

7. Silva RM, Beck CLC, Magnago TSBS, et al. Trabalho noturno e a saúde dos enfermeiros. Esc. Anna Nery. 2011; 15(2):270-276.

8. Fischer FM, Moreno CRC, Rotenberg L. Trabalho em turnos e noturno na sociedade 24 horas. São Paulo Perspec. [internet]. 2003 [acesso em 2018 jan 7]; 17(1)34:46. Disponível em: http://www.scielo.br/pdf/ spp/v17nl/v17nla04.pdf.

9. Silva RM, Beck CLC, Guido LA, et al. Análise Quantitativa da satisfação profissional dos enfermeiros que atuam no período noturno. Texto \& Contexto da Enferm. [internet] 2009 [acesso em 2018 jan 3]; 18(2):298-305. Disponível em: http://dx.doi. org/10.1590/S0104-07072009000200013.

10. Lück H. Metodologia de projetos: uma ferramenta de planejamento e gestão. 9. ed. Petrópolis: Vozes; 2008.

11. Kühn, K. Gentileza Cura? Como pequenos gestos podem ajudar na organização de relações motivadoras para o trabalho na Higienização no Hospital Nossa Senhora da Conceição [monografia] [internet]. Porto
Alegre: Instituto de Comunicação e Informação Científica e Tecnológica em Saúde, Fundação Oswaldo Cruz; 2010. 41 p. [acesso em 2018 jan 10]. Disponível em: http://arca.icict.fiocruz.br/handle/icict/3230.

12. Coscrato G, Pina JC, Mello DF. Utilização de atividades lúdicas na educação em saúde: uma revisão integrativa da literatura. Acta Paul Enferm. 2010; 23(2):257-263.

13. Gallo CMC. Desvelando fatores que afetam a satisfação e a insatisfação no trabalho de uma equipe de enfermagem [dissertação] [internet]. Rio Grande do Sul: Universidade Federal do Rio Grande. Rio Grande do Sul; 2005. 214 p. [acesso em 2018 jan 3]. Disponível em http://repositorio.furg.br/bitstream/handle/1/3542/claudiagallo.pdf?sequence=1.

14. Barros AJP. Projeto de pesquisa: propostas metodológicas. 23. ed. Petrópolis: Vozes; 2014.

15. Moraes DR. Saúde e trabalho em turno noturno: possibilidades e limites na avaliação de auxiliares de enfermagem - um estudo de caso [dissertação] [internet]. Porto Alegre: Universidade Federal do Rio Grande do Sul. Porto Alegre; 2004. 101 p. [acesso em 2018 jan 3]. Disponível em: http://hdl.handle.net/10183/6507.

16. Davel E, Vergara SC, organizadores Gestão com pessoas e subjetividade. 7. ed. São Paulo: Atlas; 2014.

\footnotetext{
Recebido em 31/07/2018

Aprovado em 26/02/2019

Conflito de interesses: inexistente

Suporte financeiro: não houve
} 